\title{
Circulating Spexin levels in pregnant women with and without gestational diabetes
}

\author{
Coskun Simsir ${ }^{1}$, Müberra Namlı Kalem ${ }^{2 *}$, Ziya Kalem ${ }^{3}$, Turgut Var ${ }^{1}$, Batuhan Bakırarar ${ }^{4}$, \\ Bugra Coskun', Bora Coskun ${ }^{1}$
}

\author{
${ }^{1}$ Department of Obstetrics and Gynecology, Liv Hospital Ankara, Ankara, Turkey \\ ${ }^{2}$ Department of Obstetrics and Gynecology, Bahcesehir University, Istanbul, Turkey \\ ${ }^{3}$ Department of Obstetrics and Gynecology, Istinye University Liv Hospital Bahcesehir, Istanbul, Turkey \\ ${ }^{4}$ Department of Biostatistics, Ankara University, Ankara, Turkey
}

Received: 04 August 2019

Revised: 05 September 2019

Accepted: 09 Septemnber 2019

\section{*Correspondence:}

Dr. Müberra Namlı Kalem,

E-mail: muberranamli@hotmail.com

Copyright: () the author(s), publisher and licensee Medip Academy. This is an open-access article distributed under the terms of the Creative Commons Attribution Non-Commercial License, which permits unrestricted non-commercial use, distribution, and reproduction in any medium, provided the original work is properly cited.

\begin{abstract}
Background: Several previous studies suggest that SPX plays a role in appetite control and body weight and blood glucose regulation. The aim of this study to determine SPX levels in healthy pregnancies and in gestational diabetes (GDM) and to investigate the association of SPX levels with weight gain and lipid and glucose metabolism in subjects with and without GDM.

Methods: A total of 44 women with GDM and 44 women without GDM were randomly enrolled who applied for GDM screening during the $24-28^{\text {th }}$ week of pregnancy. Demographics, blood glucose and lipid profiles and Spexin levels were compared between groups.

Results: The mean age, BMI, and weight gain during pregnancy were higher in the GDM group. The LDL cholesterol, Hba1c, SPX and glucose levels in response to OGTT were higher in the GDM group. The SPX levels were correlated with Hbalc and blood glucose levels after OGTT, and were not correlated with the age, BMI, weight gain during pregnancy, lipid parameters, and fasting blood glucose levels in the whole study population.

Conclusions: SPX levels were higher in the GDM group compared with non-GDM group and SPX levels were correlated with HbA1c levels and post-OGTT glucose levels but not with fasting glucose levels.
\end{abstract}

Keywords: Blood glucose, Gestational diabetes, HbA1c, Lipid profiles, OGTT, Spexin

\section{INTRODUCTION}

A novel peptide hormone Spexin (SPX) is initially identified using a computational method based on the Markov model screening performed to identify novel biologically active peptides which were later confirmed in microarray studies conducted in animals. ${ }^{1,2}$ Several studies in human and animals have demonstrated that
SPX is expressed in various tissues and organs including the gastrointestinal tract, liver, lungs, heart, brain, pancreas, adipose tissues, muscles, testis, and ovaries. ${ }^{1,3-5}$

The widespread tissue distribution of SPX imply that it may have a wide range of functions and several studies have been performed to investigate these biological functions. ${ }^{6-9}$ Several previous studies performed in 
various species suggests that SPX plays a role in appetite control and body weight and blood glucose regulation. ${ }^{10}$

Nutrition physiology and blood glucose regulation are among the most investigated topics of human metabolism and day by day a new peptide is discovered to be associated with these. ${ }^{11,12}$ Human studies investigating the role of SPX in human metabolism has recently become a current issue. Several studies investigating the role of SPX in the complex network of nutrition, blood glucose regulation, lipid metabolism, and weight gain are under way. ${ }^{2,13}$ Several studies investigating the role of SPX in pathological conditions such as obesity, metabolic syndrome, and diabetes are also under way. ${ }^{14-17}$ On the other hand, studies investigating the changes in the expression of SPX under varying conditions of pregnancy are scarce. $^{18}$

The present study was carried out to determine SPX levels in healthy pregnancies and in gestational diabetes (GDM) and to investigate the association of SPX levels with weight gain and glucose and lipid metabolism in subjects with and without GDM.

\section{METHODS}

In our cross-sectional designed study, a total of 44 women with GDM and 44 women without GDM were randomly enrolled among pregnant women above 18 years old and with antenatal surveillance who applied for GDM screening during the $24-28^{\text {th }}$ week of their pregnancy. The exclusion criteria were a diagnosis of diabetes before the pregnancy or before the aforementioned GDM screening period, multiple pregnancy, hypertension, chronic inflammatory conditions, and use of corticosteroids. The participants were informed before the study and written informed consent was obtained. The study was approved by the Ethics Committee of Liv Hospital Ankara.

A questionnaire consisting of demographic information, medical history, history of diabetes mellitus, medication use, smoking, and parity was administered to the participants.

At the $24-28^{\text {th }}$ weeks of gestation, an oral glucose tolerance test (OGTT) was performed with the ingestion of $75 \mathrm{~g}$ glucose following an overnight fast. Venous whole blood glucose levels were measured at 0,60 , and $120 \mathrm{~min}$ after oral glucose ingestion. The International Association for Diabetes in Pregnancy Society Group (IADPSG) and WHO guidelines were used for GDM diagnose. The participants were considered to have GDM if they had one or more of the following: fasting glucose $\geq 92 \mathrm{mg} / \mathrm{dl}, 1$ hour glucose $\geq 180 \mathrm{mg} / \mathrm{dl}$, or 2 hour glucose $\geq 153 \mathrm{mg} / \mathrm{dl} .{ }^{19,20}$

Blood samples were taken before OGTT. Various parameters were analyzed in these bloods. The lipid profile and glucose level were measured using a chemical analyzer (Konelab, Espoo, Finland). Circulating SPX measurements were carried out using an enzyme-linked immunoassay (ELISA) following the manufacturer protocol (Sunredbio; Shanghai Sunred Biological Technology, China) with a linear range of 0.11$1.07 \mathrm{ng} / \mathrm{ml}$, an intra assay variation of $<10 \%$ and an interassay variation of $<15 \%$. The Coulter LH 750 device (Beckman Coulter, Brea, CA) was used for the complete blood count (CBC) analysis for detecting the concentration of hemoglobin concentration as $\mathrm{g} / \mathrm{dl}$. $\mathrm{HbA} 1 \mathrm{c}$ concentrations were measured by a commercially available HPLC method.

\section{Statistical analysis}

All statistical analyses were performed using the SPSS for Windows version 11.5 (SPSS Inc., Chicago, IL). The compatibility of data with normal distribution was examined graphically and with the Kolmogorov-Smirnov test. Data are presented as mean \pm standard deviation for normally distributed continuous variables, median (minimum-maximum) for non-normally distributed continuous variables, and count and percentage for categorical variables. The Student-t test was used to compare continuous variables with normal distribution and the Mann Whitney $U$ test was used to compare continuous variables with skewed distribution. The Chi Square test was used to compare qualitative variables. The relationship between quantitative variables were tested using the Spearmans's Rho test. A P value $<0.05$ was considered statistically significant.

\section{RESULTS}

A total of 88 pregnant women with a mean age of $29.81 \pm 5.63$ were enrolled to this study. The descriptive data including the age, BMI, parity, gestational week, weight gain during pregnancy, and blood pressure measurements were presented in comparison between the study groups in (Table 1). The mean age, BMI, and weight gain during pregnancy were higher in the GDM group ( $<<0.001$ for all comparisons). Parity, pregnancy week, blood pressure measurements, and frequency of smoking were similar between the groups.

The laboratory data are compared between the study groups in Table 2, the groups were compared in terms of metabolic parameters with potential effects on hemoglobin and blood glucose levels and lipid profile (Table 2). The LDL cholesterol, Hbalc, and SPX levels and glucose levels in response to OGTT were higher in the GDM group $(\mathrm{p}=0.038, \mathrm{p}<0.001, \mathrm{p}=0.042$, and $\mathrm{p}$ $<0.001$, respectively).

The SPX levels were correlated with blood glucose and Hba1c levels after OGTT, and were not correlated with the age, BMI, weight gain during pregnancy, lipid parameters, and fasting blood glucose levels in the whole study population (Table 3). The correlations between SPX and fasting blood glucose, OGTT results, and Hba1c 
in both groups are listed in Table 4. The SPX levels had strong correlations with Hba1c in the GDM group, nonGDM group, and whole study population $(r=0.92, r=0.71$ and $\mathrm{r}=0.849$, respectively, $\mathrm{p}<0.001$ for all correlations). The correlation between the SPX and Hbalc levels is shown as a graph in Figure 1 and Figure 2.

Table 1: Demographic characteristics of patients in the study groups.

\begin{tabular}{|c|c|c|c|c|c|}
\hline \multirow{2}{*}{ Variables } & \multicolumn{2}{|l|}{ GDM (n:44) } & \multicolumn{2}{|c|}{ Control (n:44) } & \multirow{2}{*}{ p value } \\
\hline & Mean \pm SD & Median (Min.-Max.) & Mean+SD & Median (Min.-Max.) & \\
\hline Age (years) & $32.45 \pm 5.19$ & $32.00(22.00-43.00)$ & $27.16 \pm 4.79$ & $26.00(19.00-39.00)$ & $<0.001^{\mathrm{a}}$ \\
\hline BMI $\left(\mathrm{kg} / \mathrm{m}^{2}\right)$ & $21.13 \pm 4.97$ & $31.01(21.48-44.08)$ & $26.23 \pm 4.16$ & $25.67(17.26-35.50)$ & $<0.001^{\mathrm{a}}$ \\
\hline Weight gain (kg) & $9.39 \pm 3.23$ & $9.00(5.00-17.00)$ & $6.68 \pm 2.97$ & $6.00(2.00-15.00)$ & $<0.001^{\mathrm{b}}$ \\
\hline Gestational age (week) & $26.14 \pm 2.32$ & $25.50(24.00-28.00)$ & $25.55 \pm 1.49$ & $25.00(24.00-28.00)$ & $0.360^{\mathrm{b}}$ \\
\hline Parity (n) & $2.09 \pm 1.01$ & $2.00(1.00-4.00)$ & $2.50 \pm 1.23$ & $2.50(1.00-6.00)$ & $0.135^{\mathrm{b}}$ \\
\hline $\begin{array}{l}\text { Systolic blood pressure } \\
(\mathrm{mmHg})\end{array}$ & $112.00 \pm 14.7$ & $112.50(96.00-128.00)$ & $110.7 \pm 12.0$ & $111.70(95.50-125.70)$ & $0.924^{\mathrm{a}}$ \\
\hline $\begin{array}{l}\text { Systolic blood pressure } \\
(\mathrm{mmHg})\end{array}$ & $66.50 \pm 9.5$ & $66.70(62.40-74.80)$ & $64.90 \pm 9.7$ & $65.60(64.40-78.50)$ & $0.236^{\mathrm{a}}$ \\
\hline Smoking (n) & $7.50 \pm 6.41$ & $5.00(2.00-20.00)$ & $6.00 \pm 7.67$ & $2.00(1.00-20.00)$ & $0.289^{b}$ \\
\hline
\end{tabular}

a:Student-t test, b:Mann Whitney U test.

Table 2: Laboratory results in the GDM and non-GDM groups.

\begin{tabular}{|c|c|c|c|c|c|}
\hline \multirow[b]{2}{*}{ Variables } & \multicolumn{2}{|l|}{ GDM } & \multicolumn{2}{|l|}{ Control } & \multirow{2}{*}{ p value } \\
\hline & Mean \pm SD & Median (Min.-Max.) & Mean \pm SD & Median (Min.-Max.) & \\
\hline Hemoglobin & $11.52 \pm 1.13$ & $11.50(7.90-13.50)$ & $11.36 \pm 1.10$ & $11.55(8.80-13.40)$ & $0.513^{\mathrm{a}}$ \\
\hline LDL-cholesterol & $95.20 \pm 21.45$ & $90.50(59.00-153.00)$ & $85.57 \pm 21.48$ & $85.00(33.00-135.00)$ & $0.038^{\mathrm{a}}$ \\
\hline HDL-cholesterol & $44.50 \pm 9.67$ & $42.00(27.00-67.00)$ & $47.98 \pm 10.27$ & $47.00(29.00-72.00)$ & $0.106^{\mathrm{a}}$ \\
\hline Triglyceride & $104.39 \pm 42.90$ & $93.50(38.00-212.00)$ & $92.84 \pm 42.72$ & $86.50(38.00-241.00)$ & $0.186^{\mathrm{b}}$ \\
\hline Total cholesterol & $160.58 \pm 28.63$ & $154.50(117.00-238.60)$ & $152.11 \pm 32.19$ & $145.30(97.00-218.20)$ & $0.196^{\mathrm{a}}$ \\
\hline $\begin{array}{l}\text { Fasting plasma } \\
\text { glucose }\end{array}$ & $83.52 \pm 10.23$ & $81.50(69.00-110.00)$ & $82.23 \pm 8.19$ & $82.00(64.00-98.00)$ & $0.861^{\mathrm{b}}$ \\
\hline $\begin{array}{l}\text { One hour after } \\
75 \mathrm{~g} \text { glucose load }\end{array}$ & $163.52 \pm 17.18$ & $164.50(141.00-205.00)$ & $118.34 \pm 15.44$ & $121.50(79.00-189.00)$ & $<0.001^{b}$ \\
\hline $\begin{array}{l}\text { Two hours after } \\
75 \mathrm{~g} \text { glucose load }\end{array}$ & $176.69 \pm 18.49$ & $163.40(124.40-212.00)$ & $115.20 \pm 10.64$ & $125.20(94.20-176.60)$ & $0.001^{\mathrm{b}}$ \\
\hline HbA1c $(\%)$ & $6.69 \pm 1.99$ & $6.40(4.40-12.00)$ & $5.23 \pm 0.66$ & $5.20(4.10-6.70)$ & $0.001^{\mathrm{b}}$ \\
\hline Spexin & $3225.77 \pm 4568.78$ & $825.00(467.50-17186.2$ & $1028.94 \pm 1299.37$ & $637.50(239.08-17186.21$ & $0.042^{\mathrm{b}}$ \\
\hline
\end{tabular}

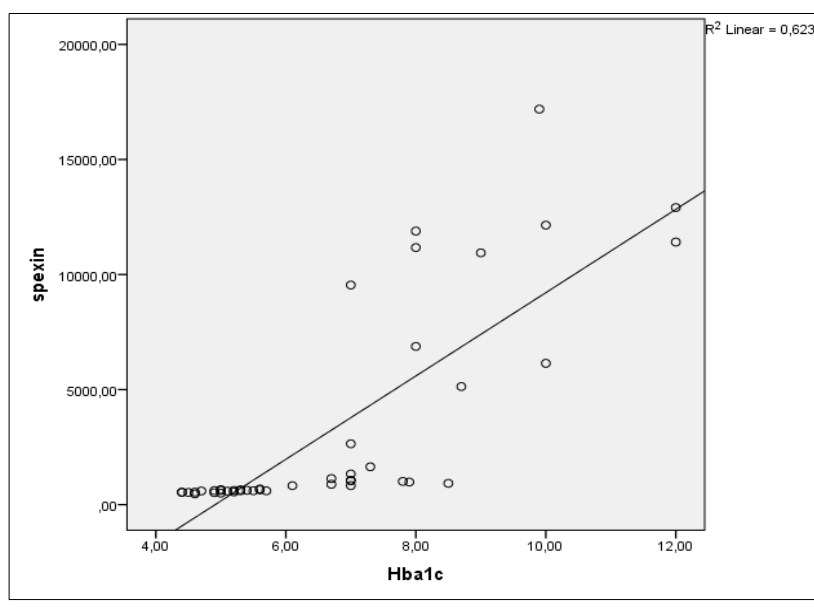

Figure 1: Correlation graph of Spexin and Hba1c in the GDM group.

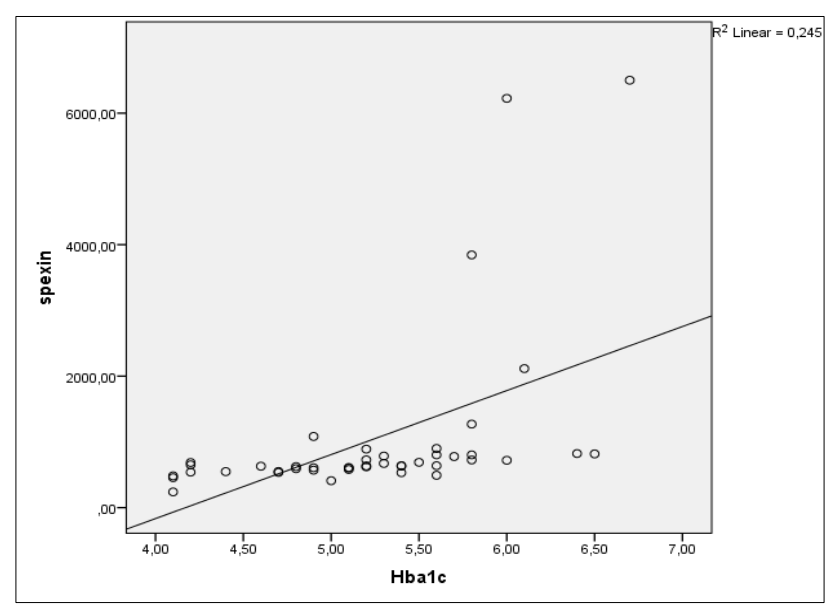

Figure 2: Correlation graph of Spexin and Hba1c in the control group. 
Table 3: Correlation of the variables with Spexin (in the whole study population).

\begin{tabular}{|c|c|c|}
\hline Variables & & Spexin \\
\hline \multirow[t]{2}{*}{ Age } & $\begin{array}{l}\text { Correlation } \\
\text { Coefficient }\end{array}$ & 0.170 \\
\hline & $\mathrm{p}$ value & 0.113 \\
\hline \multirow[t]{2}{*}{ BMI } & $\begin{array}{l}\text { Correlation } \\
\text { Coefficient }\end{array}$ & 0.050 \\
\hline & $\mathrm{p}$ value & 0.545 \\
\hline \multirow[t]{2}{*}{ Weight gain (kg) } & $\begin{array}{l}\text { Correlation } \\
\text { Coefficient }\end{array}$ & 0.197 \\
\hline & $\mathrm{p}$ value & 0.066 \\
\hline \multirow{2}{*}{ LDL-cholesterol } & $\begin{array}{l}\text { Correlation } \\
\text { Coefficient }\end{array}$ & 0.042 \\
\hline & $\mathrm{p}$ value & 0.696 \\
\hline \multirow[t]{2}{*}{ HDL-cholesterol } & $\begin{array}{l}\text { Correlation } \\
\text { Coefficient }\end{array}$ & 0.024 \\
\hline & $\mathrm{p}$ value & 0.821 \\
\hline \multirow[t]{2}{*}{ Triglyceride } & $\begin{array}{l}\text { Correlation } \\
\text { Coefficient }\end{array}$ & 0.020 \\
\hline & $\mathrm{p}$ value & 0.854 \\
\hline \multirow[t]{2}{*}{ Total cholesterol } & $\begin{array}{l}\text { Correlation } \\
\text { Coefficient }\end{array}$ & 0.060 \\
\hline & $\mathrm{p}$ value & 0.581 \\
\hline \multirow[t]{2}{*}{ Fasting plasma glucose } & $\begin{array}{l}\text { Correlation } \\
\text { Coefficient }\end{array}$ & 0.069 \\
\hline & $\mathrm{p}$ value & 0.523 \\
\hline \multirow{2}{*}{$\begin{array}{l}1 \text { hour after } 75 \mathrm{~g} \text { glucose } \\
\text { load }\end{array}$} & $\begin{array}{l}\text { Correlation } \\
\text { Coefficient }\end{array}$ & 0.253 \\
\hline & $\mathrm{p}$ value & 0.017 \\
\hline \multirow{2}{*}{$\begin{array}{l}2 \text { hours after } 75 \mathrm{~g} \text { glucose } \\
\text { load }\end{array}$} & $\begin{array}{l}\text { Correlation } \\
\text { Coefficient }\end{array}$ & 0.845 \\
\hline & $\mathrm{p}$ value & $<0.001$ \\
\hline \multirow[t]{2}{*}{ HbA1c $(\%)$} & $\begin{array}{l}\text { Correlation } \\
\text { Coefficient }\end{array}$ & 0.845 \\
\hline & $\mathrm{p}$ value & $<0.001$ \\
\hline
\end{tabular}

\section{DISCUSSION}

In the present study, the SPX levels and the associations between SPX levels and weight and lipid and glucose levels were investigated in women with and without GDM. SPX levels were significantly higher in the GDM group than the non-GDM group and there was a close relationship between the SPX levels and BMI, weight gain during pregnancy, and lipid levels. Whereas there was no correlation between fasting glucose levels and SPX levels, the glucose levels after OGTT test were correlated with the SPX levels in the GDM group and the Hba1c levels were correlated with the SPX levels in both study groups.

No correlation between the SPX levels and age was found in the present study. Lin et al, reported a negative association between age and SPX levels, but their study included only 68 healthy adult women. ${ }^{13}$ In line with the findings of the present study, Gu et al, and Kumar et al, did not find an association between age and SPX levels. ${ }^{16,17}$ There is not sufficient number of studies to come to a strict conclusion about the association of age with SPX levels. Further studies with a long duration and wide age-range are needed.

The SPX levels were not correlated with BMI or weight gain during pregnancy in the present study. Lin et al, reported that SPX levels were negatively correlated with BMI and fasting glucose levels and speculated that SPX levels could predict obesity and diabetes. ${ }^{13}$

Several studies suggest a negative relationship between the SPX levels and obesity. Kolodziejskii et al, found such a negative relationship in women with obesity and insulin resistance and Kumar et al, reported such an association obese children. ${ }^{16,21}$

Table 4: Correlation of study variables with Spexin in the GDM and non-GDM groups.

\begin{tabular}{|lllll|}
\hline Parameters & GDM Group & & Control Group & \\
\hline & Correlation coefficient & p value & Correlation coefficient & p value \\
\hline Fasting plasma glucose & 0.248 & 0.104 & -0.150 & 0.332 \\
\hline 1 hour after 75g glucose load & 0.344 & 0.022 & -0.089 & 0.567 \\
\hline 2 hour after 75g glucose load & 0.628 & 0.046 & 0.213 & 0.651 \\
\hline HbA1c $(\%)$ & 0.924 & $<0.001$ & 0.719 & $<0.001$ \\
\hline
\end{tabular}

Walevski et al, reported that SPX inhibited long chain fatty acid intake in the adipocytes in a non-diabetic mouse model. ${ }^{2}$ They also reported that SPX treatment resulted in weight reduction and improvement in glucose tolerance and insulin resistance. They suggested that SPX is a body-weight control factor secreted by the adipocytes.
Jasmine et al, suggested that SPX might serve as an adipokine with function on energy balance/metabolism and with potential application for obesity treatment. ${ }^{22}$

The contrast between these findings in the literature suggesting a negative association between SPX and weight gain and the findings of the present study may be 
explained by the fact that the study population consisted of pregnant women. The physiological differences regarding regulation of various metabolic factors between pregnant and non-pregnant women may explain the difference between these studies.

Several recent studies have shed light on the link between SPX and lipid and glucose metabolism..$^{10,14}$

SPX is reported to reduce fatty acid uptake in the adipose tissue and liver, increase lipid oxidation, and have a negative association with triglyceride and LDL cholesterol levels. ${ }^{17,22,23}$ In the present study, no association between SPX and blood lipid levels was found. To the best of our knowledge, only one previous study investigated SPX levels in GDM and reported that SPX had no correlation with lipid levels in the GDM group but it was positively correlated with triglyceride and LDL cholesterol levels in the non-GDM group. ${ }^{14}$

Several studies investigated the association of SPX with glucose metabolism and reported that SPX improved glucose tolerance and insulin resistance in type 2 diabetes; SPX levels were low in type 2 diabetes; and there was a negative correlation between SPX levels and insulin and glucagon levels. ${ }^{15,22}$ In pancreatic islet cells, SPX immunoreactivity was reported by Mirabeau et al, to be co-localized with insulin in secretory vesicles, implying that SPX can be released together with insulin. ${ }^{1}$

In the present study, insulin levels were not measured and fasting blood glucose and HbA1c levels and OGTT results were utilized to evaluate glucose metabolism. The reason for testing $\mathrm{HbA1c}$ levels in the present study was the fact that recent studies suggest that HbAlc may be used as a marker predictive of GDM. ${ }^{24}$ There was no association between fasting glucose levels and SPX in the GDM or non-GDM groups in the present study. The glucose levels in the OGTT were positively correlated with SPX in the GDM group, but this association was not present in the non-GDM group. However, HbA1c levels were positively correlated with SPX both in the GDM and non-GDM groups.

Wong et al, reported that SPX levels increased along with blood glucose and insulin levels after food intake and played a role in the development of feeling of satiety in their study in fish. ${ }^{5}$ Actually, the functional link between feeding and SPX is not clear today. Some recent research suggested that SPX is a postprandial signal. Ma et al, reported that glucose, insulin, and SPX levels increased concomitantly after feeding in their study in goldfish. ${ }^{8}$ They also reported an increase in SPX gene expression and SPX production in the liver. They reported that peripheral SPX levels increased after feeding and speculated that SPX may have an anorexigenic effect on the brain. ${ }^{8}$

In the present study, SPX levels were correlated with blood glucose levels in the group with impaired glucose tolerance but this was not true for the non-GDM group.
On the other hand, HbA1c levels were positively correlated with SPX in both groups. These findings support the notion that SPX is released postprandially. The parallel increase in SPX levels with increased HbA1c levels also suggest that SPX has a role in reduction of blood glucose levels.

The presence of a complex regulatory network between SPX and feeding which also involves the glucose and lipid metabolisms is a recent notion suggested by the present study and several others. It is not clear whether there is a cause and effect relationship between SPX and pathological conditions such as diabetes, obesity, and metabolic syndrome. Also, the change pattern of the SPX expression in these conditions is not clear. The effect of pregnancy on SPX expression and circulating SPX levels and the impact of GDM on the multiple biofunctions of SPX are the potential topics of future studies. The most important limitation of the present study is the crosssectional nature which makes drawing causal conclusions about the role of SPX in GDM difficult.

\section{CONCLUSION}

In conclusion, SPX levels were higher in the GDM group compared with the non-GDM group and SPX levels were correlated with HbA1c levels and post-OGTT glucose levels but not with fasting glucose levels. These findings suggest that SPX is a postprandial signal which plays a role in regulation of blood glucose levels after nutrition. Further large scale studies are needed to come to strict conclusions about the role of SPX in the complex network of glucose and lipid metabolism in pregnant women and GDM.

Funding: No funding sources Conflict of interest: None declared

Ethical approval: The study was approved by the Institutional Ethics Committee

\section{REFERENCES}

1. Mirabeau O, Perlas E, Severini C, Audero E, Gascuel $\mathrm{O}$, Possenti R, et al. Identification of novel peptide hormones in the human proteome by hidden Markov model screening. Genome Res. 2007;17(3):320-7.

2. Walewski JL, Ge F, Lobdell IV H, Levin N, Schwartz GJ, Vasselli JR, et al. Spexin is a novel human peptide that reduces adipocyte uptake of long chain fatty acids and causes weight loss in rodents with diet-induced obesity. Obesity. 2014;22(7):1643-52.

3. Porzionato A, Rucinski M, Macchi V, Stecco C, Sarasin G, Sfriso MM, et al. Spexin is expressed in the carotid body and is upregulated by postnatal hyperoxia exposure. In: Arterial Chemoreception. Springer. 2012:207-213.

4. Rucinski M, Porzionato A, Ziolkowska A, Szyszka M, Macchi V, De Caro R, et al. Expression of the spexin gene in the rat adrenal gland and evidences 
suggesting that spexin inhibits adrenocortical cell proliferation. Peptides. 2010;31(4):676-82.

5. Wong MK, Sze KH, Chen T, Cho CK, Law HC, Chu IK, et al. Goldfish spexin: solution structure and novel function as a satiety factor in feeding control. Am J Physiol-Endocrinol Metabol. 2013;305(3):E348-E366.

6. Liu Y, Li S, Qi X, Zhou W, Liu X, Lin H, et al. A novel neuropeptide in suppressing luteinizing hormone release in goldfish, Carassius auratus. Mol Cellular Endocrinol. 2013;374(1-2):65-72.

7. Wu H, Lin F, Chen H, Liu J, Gao Y, Zhang X, et al. Ya-fish (Schizothorax prenanti) spexin: identification, tissue distribution and mRNA expression responses to periprandial and fasting. Fish Physiol Biochem. 2016;42(1):39-49.

8. Ma A, He M, Bai J, Wong MK, Ko WK, Wong AO. Dual role of insulin in spexin regulation: functional link between food intake and spexin expression in a fish model. Endocrinol. 2017;158(3):560-77.

9. Zheng B, Li S, Liu Y, Li Y, Chen H, Tang H, et al. Spexin suppress food intake in zebrafish: evidence from gene knockout study. Scient Repo. 2017;7(1):14643.

10. Ma A, Bai J, He M, Wong AO. Spexin as a neuroendocrine signal with emerging functions. General Comp Endocrinol. 2018;265:90-6.

11. Cinti S. Anatomy and physiology of the nutritional system. Mol Aspects Med Else. 2019:83-100.

12. Dash S, Xiao C, Morgantini C, Lewis GF. New insights into the regulation of chylomicron production. Ann Rev Nutr. 2015;35:265-94.

13. Lin CY, Huang T, Zhao L, Zhong LL, Lam WC, Fan $\mathrm{BM}$, et al. Circulating spexin levels negatively correlate with age, BMI, fasting glucose, and triglycerides in healthy adult women. J Endo Society. 2018;2(5):409-19.

14. Al-Daghri NM, Alenad A, Al-Hazmi H, Amer OE, Hussain SD, Alokail MS. Spexin levels are associated with metabolic syndrome components. Dis Mark. 2018.

15. Hodges SK, Teague AM, Dasari PS, Short KR. Effect of obesity and type 2 diabetes, and glucose ingestion on circulating spexin concentration in adolescents. Pediater Diabet. 2018;19(2):212-6.

16. Kumar S, Hossain J, Nader N, Aguirre R, Sriram S, Balagopal PB. Decreased circulating levels of spexin in obese children. J Clin Endocrinol Metabol. 2016;101(7):2931-6.
17. Gu L, Ma Y, G20u M, Zhang Y, Yan S, Li N, et al. Spexin peptide is expressed in human endocrine and epithelial tissues and reduced after glucose load in type 2 diabetes. Peptides. 2015;71:232-9.

18. Al-Daghri NM, Al-Hazmi HA, Al-Ajlan A, Masoud MS, Al-Amro A, Al-Ghamdi A, et al. Associations of spexin and cardiometabolic parameters among women with and without gestational diabetes mellitus. Saudi J Biol Sci. 2018;25(4):710-4.

19. International Association of Diabetes and Pregnancy Study Groups Consensus Panel. International association of diabetes and pregnancy study groups recommendations on the diagnosis and classification of hyperglycemia in pregnancy. Diabetes Care. 2010;33(3):676-82.

20. Agarwal M, Dhatt G, Othman Y. Gestational diabetes: differences between the current international diagnostic criteria and implications of switching to IADPSG. J Diab Compli. 2015;29(4):544-9.

21. Kołodziejski P, Pruszyńska-Oszmałek E, Korek E, Sassek M, Szczepankiewicz D, Kaczmarek P. Serum levels of spexin and kisspeptin negatively correlate with obesity and insulin resistance in women. Physiol Res. 2018;67(1):45-56.

22. Jasmine FG, Walewski J, Anglade D, Berk P. Regulation of hepatocellular fatty acid uptake in mouse models of fatty liver disease with and without functional leptin signaling: roles of NfKB and SREBP-1C and the effects of spexin. In: Seminars in liver disease, Thieme Med Pub. 2016:360-372.

23. Berk PD, Verna EC. Nonalcoholic fatty liver disease: lipids and insulin resistance. Clinics Liver Dis. 2016;20(2):245-62.

24. Saglam B, Uysal S, Sozdinler S, Dogan OE, Onvural B. Diagnostic value of glycemic markers HbA1c, 1, 5 -anhydroglucitol and glycated albumin in evaluating gestational diabetes mellitus. Ther Adv Endocrinol Metabol. 2017;8(12):161-7.

Cite this article as: Simsir C, Kalem MN, Kalem Z, Var T, Bakırarar B, Coskun B, et al. Circulating Spexin levels in pregnant women with and without gestational diabetes. Int J Reprod Contracept Obstet Gynecol 2019;8:4056-61. 